\title{
Economic Evaluation of Severe Anaemia: Review-Based Recommendations and a Conceptual Framework
}

\author{
Authors: \\ Dimitrios Tomaras, William Lemay, *Gabriel Tremblay \\ Purple Squirrel Economics, Montreal, Canada \\ *Correspondence to gabrieltremblay@pshta.com \\ Disclosure: \\ The authors have declared no conflicts of interest. \\ Received: \\ 16.04 .20 \\ Accepted: \\ 08.06 .20 \\ Keywords: \\ Anaemia, conceptual framework, red blood cell (RBC) disorders. \\ Citation: \\ EMJ. 2020;5[3]:45-54.
}

\section{Abstract}

Objective: Novel anaemia treatments have greatly improved patient outcomes in the last decade and have also undergone economic evaluations in various settings using heterogenous model structures, costs, and inputs. The objectives were to review published economic evaluation studies in major red blood cell disorders, identify limitations in the applied methodology, provide a set of recommendations, and produce a conceptual framework for future economic research in this disease area.

Methods: A targeted search was conducted for economic literature evaluating treatments in major red blood cell disorders related to anaemia. Disorders included autoimmune haemolytic anaemia, $\beta$-thalassaemia, chemotherapy-induced anaemia, anaemia in chronic kidney disease, and severe aplastic anaemia. Budget impact models and cost-effectiveness and cost-utility analyses were considered. Modelling assumptions regarding the model structure, time horizon, perspective, and type of costs were reviewed and recommendations and a conceptual framework for future economic analyses were created.

Results: A total of four budget impact models, nine cost-utility analyses, and four cost-effectiveness analyses were investigated. A major limitation was that the included costs varied significantly across studies. Costs which were rarely included, and generally should be considered, were related to adverse events, mortality, and productivity. Additionally, relationships between levels of serum ferritin, hepatic or total body iron, and haemoglobin with long-term complications and mortality were rarely included.

Conclusion: Published economic analyses evaluating treatments for major red blood cell disorders frequently exclude vital costs. A set of recommendations and a conceptual framework will aid researchers in applying a more comprehensive approach for economic evaluations in major red blood cell disorders. 


\section{INTRODUCTION}

Anaemia is characterised by a decrease in the total amount of red blood cells (RBC) and haemoglobin $(\mathrm{Hb})$ levels, reducing the volume of oxygen transported through the blood? Several varieties of anaemia exist, and the disease pathology can be explained either as a disease-related complication (e.g., anaemia of inflammation) or as a general hereditary condition. ${ }^{2,3}$ Anaemia classifications and conditions leading to severe anaemia include autoimmune haemolytic anaemia (AlHA), $\beta$-thalassaemia, chemotherapy-induced anaemia, anaemia in chronic kidney disease (CKD), and severe aplastic anaemia (SAA); many of which are associated with early mortality.

RBC transfusions were frequently used as a standard of care in the treatment of anaemia; however, regular RBC transfusions are accompanied with serious health risks. ${ }^{4}$ Iron overloading, related to regular RBC transfusions, can lead to fatal complications including organ failure. One class of alternative therapies, erythropoiesis-stimulating agents (ESA), received U.S. Food and Drug Administration (FDA) approval in 1989 for anaemia related to chronic renal failure. ${ }^{5}$ Subsequently, a combination of ESA and RBC transfusions are generally used to treat severe anaemias. Recently, new treatment strategies have been undergoing clinical development with several novel therapies gaining regulatory approval. Novel therapies are also accompanied with high costs, which can act as potential barriers to patient access. Economic evaluations aid decision makers to assess whether the reimbursement of novel therapies would be an efficient use of limited healthcare resources and if they can be afforded with current healthcare budgets.

The purpose of this review is to identify relevant literature and explore the budgetary impacts of novel treatments for severe anaemia and whether they were found to be cost-effective. The benefit of reviewing economic literature is two-fold. Firstly, standardised cost-effectiveness analyses (CAE) in severe anaemias will allow clinicians to consider lifetime clinical outcomes, which may not be adequately captured in clinical trials, the length of which is generally limited to 1-2 years. Reviewing standardised economic evaluations would help clinicians consider long-term health implications in their decision-making process. Secondly, as novel therapies are generally very costly, it is important for clinicians to consider whether the added clinical benefit of a therapy justifies the incremental cost in settings with limited healthcare resources. Standardised economic evaluations in this disease area will allow clinicians to compare various treatments across analyses and aid decision-making while considering budgetary implications.

To the authors' knowledge, no manuscript investigating the evolution of severe anaemia treatment from an economic perspective has been published. As severe anaemia is generally a chronic disease, careful economic modelling should be employed to appropriately capture long-term disease implications.

\section{METHODS}

A targeted literature review was conducted via PubMed Central (PMC), Google Scholar, and OVID. The disease area of interest included any type of severe anaemia evaluated in a published comprehensive economic analysis. Although stem cell transplant treatments are important in this disease area, they are significantly different from ongoing, continuous therapies, which are the focus of this analysis. Differences such as cost structures and cure potential result in different designs and, for this reason, stem cell transplants are excluded from this analysis. No other limits on the type of treatments were employed. Search terms included a combination of a disease term with a study design term. Disease terms included "anemia", "beta-thalassemia", "autoimmune hemolytic anemia", "chemotherapy-induced anemia", "sickle cell disease", "chronic kidney disease anemia", and "severe aplastic anemia". Study design terms included "cost-effectiveness analysis","cost-utilityanalysis", and "budgetimpact model". Any economic outcome was included. Additional limits included studies published in English and studies published between 2010 and 2020. Subsequently, the methodology of identified studies was critically assessed. Recommendations for future economic evaluations were developed based on a critical assessment. Additionally, a conceptual framework was created to aid future economic analyses, 
building on past studies' strengths, and identifying gaps to be avoided in future research.

\section{RESULTS}

\section{Overview}

A total of 18 studies were identified which met the inclusion/exclusion criteria. The following elements were explored for each study: disease area, study design and perspective, treatments, time horizon, costs, measures of uncertainty, as well as the model structure and health states. A summary of studies is presented in Table 1.6-23

\section{Diseases}

Seven studies evaluated therapy for $\beta$-thalassaemia, one for AlHA, one for chemotherapy-induced anaemia, one for chronic heart failure-related anaemia, two for SAA, and six for CKD-related anaemia.

\section{Study Design and Perspective}

Four studies were budget impact models (BIM), four were CEA, and 10 were cost-utility analyses (CUA). From the 18 studies identified, two were Canadian, three were from the USA, two from Australia, two from Italy, and one from the UK, Thailand, China, Iran, Poland, Germany, South Korea, and Morocco, respectively. A total of 16 studies used a healthcare system perspective while two others used a societal perspective.

Table 1: Identified publications

\begin{tabular}{|c|c|c|c|c|c|c|}
\hline Disease & Country & Study & Type of study & Time horizon & Perspective & Treatment \\
\hline \multirow{7}{*}{$\beta$-thalassaemia } & UK & $\begin{array}{l}\text { Bentley et al., } \\
2013\end{array}$ & CUA & 5 years & $\begin{array}{c}\text { Healthcare } \\
\text { payer }\end{array}$ & $\begin{array}{l}\text { DFO, DFP, DFX, } \\
\text { combination } \\
\text { therapy (DFO plus } \\
\text { DFP) }\end{array}$ \\
\hline & Thailand & $\begin{array}{l}\text { Luangasanatip } \\
\text { et al., } 2011\end{array}$ & CUA & Lifetime & Societal & DFX versus DFP \\
\hline & Australia & $\begin{array}{l}\text { Karnon et al., } \\
2012\end{array}$ & CUA & 50 years & $\begin{array}{l}\text { Healthcare } \\
\text { payer }\end{array}$ & DFX versus DFO \\
\hline & China, Taiwan & Ho et al., ${ }^{9} 2013$ & CUA & 50 years & $\begin{array}{c}\text { Healthcare } \\
\text { payer }\end{array}$ & DFX versus DFO \\
\hline & Iran & 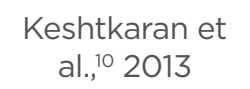 & CUA & Lifetime & Societal & DFX versus DFO \\
\hline & Poland & $\begin{array}{c}\text { Walczak et al.,"1 } \\
2013\end{array}$ & CUA & 1 year & $\begin{array}{c}\text { Healthcare } \\
\text { payer }\end{array}$ & DFX versus DFO \\
\hline & Italy & $\begin{array}{c}\text { Pepe et al., } \\
2017\end{array}$ & CUA & 5 years & $\begin{array}{l}\text { Healthcare } \\
\text { payer }\end{array}$ & DFX versus DFP \\
\hline $\begin{array}{c}\text { Autoimmune } \\
\text { haemolytic } \\
\text { anaemia }\end{array}$ & Italy & $\begin{array}{c}\text { Rognoni et al., }{ }^{13} \\
2018\end{array}$ & BIM & 3 and 5 years & $\begin{array}{l}\text { Hospital and } \\
\text { taxpayer }\end{array}$ & $\begin{array}{c}\text { Rituximab } \\
\text { originator } \\
\text { versus rituximab } \\
\text { biosimilars and SC } \\
\text { versus IV }\end{array}$ \\
\hline $\begin{array}{l}\text { Chemotherapy- } \\
\text { induced } \\
\text { anaemia }\end{array}$ & Greece & $\begin{array}{c}\text { Nikolaidi et al., }{ }^{14} \\
2013\end{array}$ & BIM & 15 weeks & $\begin{array}{l}\text { Social security } \\
\text { funds }\end{array}$ & $\begin{array}{c}\text { ESA originator } \\
\text { versus ESA } \\
\text { biosimilar }\end{array}$ \\
\hline
\end{tabular}


Table 1 continued.

\begin{tabular}{|c|c|c|c|c|c|c|}
\hline Disease & Country & Study & Type of study & Time horizon & Perspective & Treatment \\
\hline $\begin{array}{l}\text { Chronic heart } \\
\text { failure with } \\
\text { iron deficiency } \\
\text { anaemia }\end{array}$ & South Korea & Lim et al.,15 2015 & CUA & 24 weeks & $\begin{array}{c}\text { Healthcare } \\
\text { payer }\end{array}$ & $\begin{array}{c}\text { Ferric } \\
\text { carboxymaltose } \\
\text { versus placebo }\end{array}$ \\
\hline \multirow{3}{*}{$\begin{array}{c}\text { Severe aplastic } \\
\text { anaemia }\end{array}$} & USA & $\begin{array}{l}\text { Tremblay et al., }{ }^{16} \\
2019\end{array}$ & BIM & 3 years & $\begin{array}{c}\text { Private } \\
\text { healthcare } \\
\text { system }\end{array}$ & $\begin{array}{c}\text { EPAG plus ATGAM } \\
\text { plus cyclosporine } \\
\text { versus ATGAM } \\
\text { plus cyclosporine }\end{array}$ \\
\hline & Germany & $\begin{array}{l}\text { Heublein et al., }{ }^{17} \\
2013\end{array}$ & CEA & 1 year & $\begin{array}{c}\text { Healthcare } \\
\text { payer }\end{array}$ & $\begin{array}{l}\text { h-GAM (ATGAM) } \\
\text { versus R-GAM } \\
\text { (Thymoglobulin } \\
\text { [Sanofi, Paris, } \\
\text { France]) }\end{array}$ \\
\hline & USA & $\begin{array}{c}\text { Yarnoff et al., }{ }^{18} \\
2016\end{array}$ & CEA & Lifetime & $\begin{array}{c}\text { Healthcare } \\
\text { payer }\end{array}$ & $\begin{array}{c}\text { ESA for optimal } \\
\text { Hb level }\end{array}$ \\
\hline \multirow{5}{*}{$\begin{array}{c}\text { Chronic kidney } \\
\text { disease-related } \\
\text { anaemia }\end{array}$} & Australia & $\begin{array}{l}\text { Wong et al..19 } \\
2013\end{array}$ & CEA & Lifetime & $\begin{array}{c}\text { Healthcare } \\
\text { payer }\end{array}$ & $\begin{array}{l}\text { IV versus oral iron } \\
\text { supplementation }\end{array}$ \\
\hline & Canada & $\begin{array}{l}\text { Clement et al., }{ }^{20} \\
2014\end{array}$ & CUA & Lifetime & $\begin{array}{c}\text { Healthcare } \\
\text { payer }\end{array}$ & $\begin{array}{l}\text { ESA versus } \\
\text { without ESA }\end{array}$ \\
\hline & Canada & $\begin{array}{c}\text { Tsao et al., }{ }^{21} \\
2014\end{array}$ & BIM & 5 years & $\begin{array}{c}\text { Healthcare } \\
\text { payer }\end{array}$ & $\begin{array}{l}\text { ESA originator } \\
\text { versus ESA } \\
\text { biosimilar }\end{array}$ \\
\hline & Morocco & $\begin{array}{l}\text { Maoujoud et } \\
\text { al., }{ }^{22} 2016\end{array}$ & CUA & 1 year & $\begin{array}{c}\text { Healthcare } \\
\text { payer }\end{array}$ & $\begin{array}{l}\text { Continuous } \\
\text { erythropoietin } \\
\text { receptor activator } \\
\text { versus epoetin } \\
\text { beta versus RBC } \\
\text { transfusion }\end{array}$ \\
\hline & USA & $\begin{array}{l}\text { Quon et al., }{ }^{23} \\
2012\end{array}$ & CEA & 5 years & $\begin{array}{l}\text { Healthcare } \\
\text { payer }\end{array}$ & $\begin{array}{c}\text { ESA for optimal } \\
\text { Hb level }\end{array}$ \\
\hline
\end{tabular}

BIM: budget impact model; CEA: cost-effectiveness analysis; CUA: cost-utility analysis; DFX: deferasirox; DFP: deferiprone; DFO: desferrioxiamine; EPAG: eltrombopag; ESA: erythropoiesis-stimulating agent; Hb: haemoglobin; IST: immunosuppressive therapy (ATGAM plus cyclosporine); IV: intravenous; NHS: National Health Service; RBC: red blood cell; SC: subcutaneous.

\section{Treatments}

For $\beta$-thalassaemia, the study treatments assessed were various chelation therapies (deferoxamine, deferiprone, deferasirox, and combination of deferoxamine plus deferiprone).

The AIHA study compared rituximab against a biosimilar, also comparing subcutaneous versus intravenous administration. For chemotherapyinduced anaemia, ESA originators (Aranesp ${ }^{\circledR}$ [Amgen, Thousand Oaks, California, USA] [darbepoetin alpha], NeoRecormon [Roche, Basel, Switzerland] [epoetin beta], and Eprex [Janssen, Beerse, Belgium] [epoetin alpha]) were compared to biosimilars (Abseamed [MEDICE, Iserlohn, Germany] [epoetin alpha], Binocrit ${ }^{\circledR}$ [Sandoz, Holzkirchen, Germany] [epoetin alpha], and Retacrit ${ }^{\circledast}$ [Pfizer, New York City, New York, USA] [epoetin zeta]). For SAA, two identified studies assessed eltrombopag and ATGAM $^{\circ}$ (Pfizer), respectively, against immunosuppressive therapy. For CKD-related anaemia, treatments 
were related to the usage of ESA for patients on or without dialysis. For the chronic heart failure-related iron-deficient anaemia, iron supplementation was evaluated against placebo.

\section{Time Horizon}

Time horizons identified across studies ranged from 15 weeks to a lifetime. Shorter time horizons (15 weeks to 5 years) were employed in ten studies (56\%) while two used 50 year-horizons (11\%), and a lifetime horizon was used in six (33\%). As chemotherapy-induced anaemia is a non-chronic condition, a 15-week horizon was applied. Excluding chemotherapy-induced anaemia, and chronic heart failure-related anaemia, time horizons ranged from 1 year to a lifetime.

\section{Costs}

All studies included drug costs (100\%), 12 studies included administration costs (67\%), and seven studies included healthcare resource utilisation costs (39\%). Indirect costs were frequently missing from analyses, specifically, adverse events, mortality, and productivity costs. They were included in five (28\%), two (11\%), and one (6\%) studies, respectively. Administration costs were excluded in two biosimilar studies and biosimilar studies also excluded indirect costs, which were assumed to be similar for both treatment arms.

\section{Uncertainty}

A total of 15 studies (83\%) included sensitivity analyses, which assessed stochastic and deterministic uncertainty by varying inputs and testing model assumptions. Two BIM and one CUA did not report any assessment of uncertainty.

\section{Model Structure and Health States}

The model structure varied greatly across different studies. For CEA and CUA, the model structure was reported as Markov models for nine studies (50\%), microsimulations for two studies (11\%), and unreported for three studies (17\%). Four additional studies were BIM (24\%). The number of health states varied from three to seven across diseases.

\section{DISCUSSION}

\section{Overview and Conceptual Framework}

Economic evaluations in severe anaemia were reviewed with the objective of creating recommendations for individual components of future economic analyses. The lack of economic-focussed guidelines for severe anaemia demonstrates a gap in the literature. Conceptual frameworks have been developed in multiple other therapeutic areas including immune thrombocytopenia ${ }^{24}$ and acute coronary syndrome..$^{25}$ As anaemia is generally a chronic condition with long-term implications, it is vital to consider if short-term trial endpoints can accurately be extrapolated to long-term horizons and outcomes. Moreover, structural heterogeneity across economic evaluations can hinder cross-study comparisons. A validated conceptual economic framework used in future research could facilitate easier comparisons. As long-term complications are associated with severe anaemia and standard of care treatments, relevant biomarkers such as levels of $\mathrm{Hb}$ and serum ferritin should be included as proxies to quantify the long-term risk of complications.

A general conceptual framework was developed for CEA and CUA in severe anaemia. It is possible that different disease-specific considerations and economic questions would require a tailoring of the conceptual framework. However, the one presented in Figure 1 has been designed to accurately capture the implications of chronic anaemia and related RBC transfusions, including long-term complications related to iron overloading (serum ferritin proxy) and reduced or elevated $\mathrm{Hb}$, treatment-related adverse events, key costs, key efficacy measures, and important endpoints. The conceptual framework may help clinicians and formulary committees evaluate the robustness of economic analyses. This, in turn, could help formulary committees consider which treatments obtain formulary coverage and subsequently affect the clinician's ability to prescribe these treatments. Additionally, standardised economic study designs could help clinicians evaluate the long-term effectiveness of therapies across different analyses and aid clinical decision-making. 


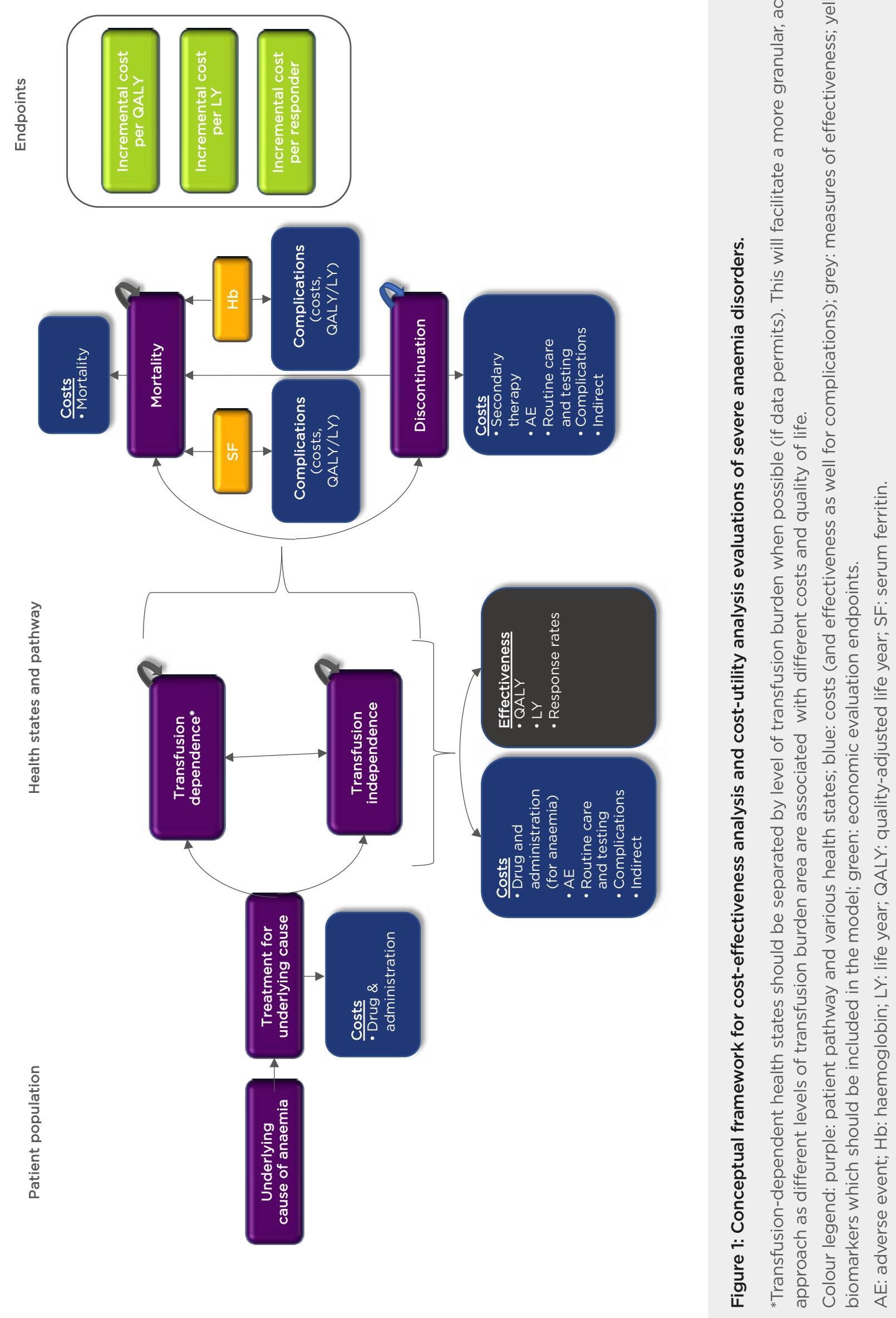


Additional components requiring further consideration are summarised in the following subsections.

\section{Treatment Comparisons}

As economic evaluations are comparative by nature, it is important to specify which techniques or trial designs were used to compare treatments and to report the source of data. Typically, trial-based data should be utilised as a source of clinical inputs for novel therapies. In cases where multiple trials are used as data sources, an indirect treatment comparison (ITC) should be considered. Naïve, unadjusted ITC could lead to bias because of differing baseline patient characteristics and trial heterogeneity. If the baseline characteristics between treatment arms are imbalanced, an ITC should be conducted. Appropriate ITC require individual patient data which is matched for baseline characteristics to another trial population using statistical techniques. Two ITC methods are recommended, including the simulated treatment comparison and the matching-adjusted indirect comparison, whose objectives are to produce a covariateadjusted treatment effect estimate. Propensity scoring and regression form the basis of their methods and both are recommended by the National Institute for Health and Care Excellence (NICE). ${ }^{26}$ One important consideration is to assess whether trial data can accurately be extrapolated to long-term outcomes. As this can vary with different types of severe anaemia and trial design, it is recommended to consult a clinical expert. ${ }^{27}$

\section{Health States}

Transfusion-dependent patients have a higher likelihood of experiencing complications than their non-dependent counterparts, potentially necessitating a greater number of hospitalisations and outpatient visits. ${ }^{28}$ Iron overload related to RBC transfusions is associated with long-term cardiac and hepatic infection and endocrine complications. ${ }^{29}$ Multiple studies found an association between quality of life and $\mathrm{Hb}$ levels in transfusion-dependent patients. ${ }^{30-32}$ Additionally, numerous studies found that complications related to iron overloading, estimated using serum ferritin, were also associated with reductions in quality of life and utility. ${ }^{33-35}$
Therefore, levels of serum ferritin and $\mathrm{Hb}$ should be accounted for throughout the horizon of the model with elevated levels of serum ferritin and reduced/elevated levels of $\mathrm{Hb}$ leading to complications and quality of life decrements. One study showed that patients with lower (9.0-10.9 g/dL) and higher (>12.0 g/dL) Hb levels have increased frequencies of adverse events and early mortality. ${ }^{20}$ These differences could be reflected in different health states. If the data permits, multiple health states with various levels of transfusion burden, serum ferritin, and hepatic or total body iron count should be used to account for higher frequency of RBC transfusions and related long-term complications. The evaluated diseases are mostly chronic by nature and long-term horizons should be prioritised. Models should also incorporate the dynamic nature of complications and patient burden, which increase with time. ${ }^{36}$

\section{Costs}

As anaemia is a chronic condition, costs which arise over an extended period should be considered. Both direct and indirect costs should be included when comparing two different treatments. Several key costs were absent from the literature. Adverse events, long-term complications, mortality, and productivity costs should be included to create a comprehensive analysis. The proposed conceptual framework enables the inclusion of numerous costs including the cost to treat the underlying cause of anaemia (e.g., $\beta$-thalassaemia), which can vary between transfusion burden, health states, and anaemia severity. A granular approach between transfusion burden health states (e.g., high versus low) is preferable if data is available, because the annual costs of RBC transfusions can vary with frequency of administration. Anaemia severity may be evaluated through iron concentration or $\mathrm{Hb}$ levels, but is economically manifested through the cost of RBC transfusions and other supporting therapies (e.g., iron chelation therapy), adverse events, long-term complications, routine care and testing, early mortality, and indirect costs.

\section{Complications and Adverse Events}

Serum ferritin is used to assess iron levels and oxygen levels are used to estimate $\mathrm{Hb}$. Depending on anaemia severity, patients may require 
frequent RBC transfusions, resulting in long-term iron overloading, long-term complications, and treatment-related adverse events. ${ }^{37}$ Examples of anaemia-related long-term complications and treatment-related adverse events include cardiovascular disease, cerebrovascular disease, and infection. ${ }^{38}$ Complications and adverse events could lead to elevated costs through more frequent hospitalisations, outpatient visits, and potentially early mortality. Levels of $\mathrm{Hb}$ were only directly considered in five economic evaluations (29\%). A modelling approach which includes dynamic rates for the risk of long-term complications based on transfusion burden and $\mathrm{Hb}$ and serum ferritin levels is recommended. A gap in the published analyses was identified as no economic studies considered the relationship between complications and serum ferritin levels.

In four identified studies, adverse events affected quality of life; however, their costs were not considered. It is recommended that economic evaluations include both cost and quality of life effects for long-term complications and adverse events.

\section{Sensitivity Analysis}

All economic evaluations should contain an uncertainty assessment. It is essential to test assumptions and quantify the stochastic effect/ probabilistic and deterministic uncertainty on the results of the analyses. Evaluations without uncertainty assessments are not comprehensive. For BIM, it is recommended to perform one-way deterministic sensitivity analyses which varies inputs individually in various scenarios. The magnitude of variance should be obtained from published literature or from consultation with disease-specific clinical experts. ${ }^{39}$ For CEA and CUA, one-way deterministic and probabilistic sensitivity analyses are also recommended. In probabilistic sensitivity analyses, all inputs should be varied simultaneously for 1,000-10,000 iterations to identify a range of incremental cost-effectiveness ratios and to estimate the probability that an incremental cost-effectiveness ratio falls under a willingness-to-pay threshold. The stochasticity of variables is assessed using their standard error and a randomly generated value across specific distributions. Appropriate distributions should be selected based on variable characteristics. Generally, the gamma distribution should be considered for costs, beta or gamma distributions for utility, and log-normal distributions if a skew to the right is needed. Uncertainty analysis is vital to assess robustness. NICE guidelines also recommend exploring the impact of uncertainty on the results of the economic analyses. ${ }^{40}$

\section{Limitations}

The proposed framework and set of recommendations were specifically designed for economic evaluations related to severe anaemia. It should be noted that disease-specific anaemias, e.g., CKD-related anaemia, could require modellers to adapt and tailor the framework by adding dialysis or kidney transplant pathways or health states, for example. The disease-specific framework may also require further adjustments based on the availability of data for the disease, for example, the availability of an association between health states and mortality. Additionally, although ITC is recommended using individual patient data, it is plausible that future modellers may have limited access to this type of data, potentially impeding the implementation of this recommendation. No economic evaluations were identified for several common anaemias including sickle cell anaemia. Notably, the Institute for Clinical and Economic Review (ICER) also released an evidence report on sickle cell disease in March 2020. The report states that sickle cell disease has been an underfunded area for research; therefore, there is limited literature on the subject. ${ }^{41}$ Additionally, it should be noted that, while the analysis is focussed on severe anaemia or conditions related to severe anaemias, anaemia may not be the sole determinant of costs and quality of life. The underlying disease would also have a significant effect. Several treatments targeting anaemia, such as iron chelation therapy, would however, require economic evaluations.

An additional limitation is regarding the validity of serum ferritin as a proxy for iron overload. Other methods, such as T2*-weighted MRI of the liver or other major organs, may capture iron overload more accurately. ${ }^{42,43}$ However, as clinical trials would frequently be the source of inputs for economic models, their relatively short durations may not allow variations of iron concentration from T2*-weighted MRI to correlate with patient quality of life, an essential 
consideration in cost-effectiveness analysis. Serum ferritin levels fluctuate more rapidly relative to $\mathrm{T} 2 *$-weighted MRI. Another reason serum ferritin is frequently used to assess the level of iron overload is its relatively low cost and ease of implementation compared with other techniques. ${ }^{44}$ Weekly or monthly T2*-weighted $\mathrm{MRI}$ is unlikely to be recommended, as fluctuations require longer periods of time. MRI is recommended every 6 to 24 months depending on the condition severity; this testing interval can be longer than typical clinical trials. ${ }^{45}$

\section{CONCLUSION}

The targeted literature review demonstrated numerous gaps in published economic evaluations for severe anaemia-related diseases. By identifying these gaps, a conceptual framework and set of recommendations were created for future economic evaluations in severe anaemia-related diseases. Key considerations for future analyses consist of the inclusion of $\mathrm{Hb}$ and iron concentration levels in the model, multiple transfusion-dependent health states (if possible), long-term complications, adverse events, early mortality, and productivity costs. Future economic analyses which use a consistent anaemia-specific framework will allow decision makers to appropriately compare various published studies, critique the robustness of their analyses and ultimately aid them in their reimbursement decision-making process to optimise the use of scarce healthcare resources.

\section{References}

1. National Heart, Lung, and Blood Institute (NHLBI). Your guide to anemia national hearth lung and blood institute. 2011. Available at: https://www.nhlbi.nih.gov/ health-topics/all-publications-andresources/your-guide-anemia. Last accessed: 31 March 2020.

2. Watson $\mathrm{R}$. The hereditary anemias. Bull N Y Acad Med. 1954;30(2):106-21.

3. Nemeth E, Ganz T. Anemia of inflammation. Hematol Oncol Clin North Am. 2014;28(4):671-81.

4. Cortés Buelvas A. Anemia and transfusion of red blood cells. Colomb Med (Cali). 2013;44(4):236-42.

5. U.S. Food and Drug Administration (FDA). Information for epogen/ procrit. 2018. Available at: https:// www.fda.gov/drugs/postmarketdrug-safety-information-patientsand-providers/informationepogenprocrit-epoetin-alfa. Last accessed: 7 April 2020.

6. Bentley A et al. Cost-utility analysis of deferiprone for the treatment of $\beta$-thalassaemia patients with chronic iron overload: a UK perspective. Pharmacoeconomics. 2013;31(9):807-22.

7. Luangasanatip $\mathrm{N}$ et al. Iron-chelating therapies in a transfusion-dependent thalassaemia population in Thailand. Clin Drug Investig. 2011;31(7):493-505

8. Karnon J et al. Lifetime cost-utility analyses of deferasirox in beta- thalassaemia patients with chronic iron overload. Clin Drug Investig 2012;32(12):805-15.

9. Ho WL et al. A pharmaco-economic evaluation of deferasirox for treating patients with iron overload caused by transfusion-dependent thalassemia in Taiwan. J Formos Med Assoc. 2013;112(4):221-9.

10. Keshtkaran A et al. Cost-utility analysis of oral deferasirox versus infusional deferoxamine in transfusion-dependent 》-thalassemia patients. Transfusion. 2013;53(8):1722-9

11. Walczak J et al. The budget impact analysis of deferasirox for the treatment of iron overload due to frequent blood transfusions in children and adolescents (age $\leq 18$ years). Value Health. 2013;16(7):A379.

12. Pepe $A$ et al. Cost-utility analysis of three iron chelators used in monotherapy for the treatment of chronic iron overload in $\beta$-thalassaemia major patients: an Italian perspective. Clin Drug Investig. 2017;37(5):453-64

13. Rognoni $\mathrm{C}$ et al. Budget impact analysis of rituximab biosimilar in Italy from the hospital and payer perspectives. Global \& Regional Health Technology Assessment. 2018; DOI:10.1177/2284240318784289.

14. Nikolaidi E et al. Budget impact analysis on erythropoiesis-stimulating agents use for the management of chemotherapy-induced anaemia in Greece. Cost Eff Resour Alloc. 2013;11(1):16.

15. Lim WH et al. Recurrent acute decompensated heart failure owing to severe iron deficiency anemia caused by inappropriate habitual bloodletting. J Cardiovasc Ultrasound. 2015;23(4):253-6.

16. Tremblay $G$ et al. Budget impact of eltrombopag as first-line treatment for severe aplastic anemia in the United States. Clinicoecon Outcomes Res. 2019;11:673-81.

17. Heublein $\mathrm{S}$ et al. Modelling cost effectiveness of horse antithymocyte globulin for treating severe aplastic anaemia in Germany. Ann of Hematol. 2013;92(6):825-30

18. Yarnoff B et al. The cost-effectiveness of anemia treatment for persons with chronic kidney disease. PLoS One. 2016;11(7):e0157323.

19. Wong $\mathrm{G}$ et al. An economic evaluation of intravenous versus oral iron supplementation in people on haemodialysis. Nephrol Dial Transplant. 2013;28(2):413-20.

20. Clement $\mathrm{F}$ et al. An economic evaluation of erythropoiesisstimulating agents in CKD. Am J Kidney Dis. 2010;56(6):1050-61.

21. Tsao $\mathrm{N}$ et al. A budget impact analysis of the introduction of 
erythropoiesis stimulating agent subsequent entry biologics for the treatment of anemia of chronic kidney disease in Canada. Can J Kidney Health Dis. 2014;1:28.

22. Maoujoud $\mathrm{O}$ et al. The cost-utility of treating anemia with continuous erythropoietin receptor activator or Epoetin versus routine blood transfusions among chronic hemodialysis patients. Int J Nephro Renovasc Dis. 2016;9:35-43.

23. Quon P et al. Cost-effectiveness of treating chronic anemia with epoetin alfa among hemodialysis patients in the United States. Health Outcomes Res Med. 2012;3(2):e79-89.

24. Dolph M et al. A decision framework for treating chronic immune thrombocytopenia with thrombopoietin receptor agonists. J Comp Eff Res. 2018;7(8):775-84.

25. Espinoza M et al. The value of heterogeneity for cost-effectiveness subgroup analysis: conceptual framework and application. Med Decis Making. 2014;34(8):951-64.

26. Phillippo D et al. Methods for population-adjusted indirect comparisons in health technology appraisal. Med Decis Making. 2018;38(2):200-11.

27. Azimpour K et al. PNS297 clinical and key opinion leaders validation in health economics model and comparative effectiveness: a guide for non-expert audience. Value in Health. 2019;22(3):S813.

28. Sahu S et al. Adverse events related to blood transfusion. Indian $J$ Anaesth. 2014;58(5):543-51.

29. Improta S et al. Transfusiondependent low-risk myelodysplastic patients receiving deferasirox: long-term follow-up. Oncol Lett. 2013:6(6):1774-8.

30. Finkelstein $\mathrm{F}$ et al. Health related quality of life and the CKD patient: challenges for the nephrology community. Kidney Int. 2009;76(9):946-52

31. Clement F et al. The impact of selecting a high hemoglobin target level on health-related quality of life for patients with chronic kidney disease: a systematic review and meta-analysis. Arch Intern Med. 2009;169(12):1104-12.

32. Foley R et al. Erythropoietin therapy, hemoglobin targets, and quality of life in healthy hemodialysis patients: a randomized trial. Clin J Am Soc Nephrol. 2009;4(4):726-33.

33. Sruamsiri R et al. Cost utility analysis of reduced intensity hematopoietic stem cell transplantation in adolescence and young adult with severe thalassemia compared to hypertransfusion and iron chelation program. BMC Health Serv Res. 2013;13:45.

34. John $M$ et al. Cost effectiveness of hematopoietic stem cell transplantation compared with transfusion chelation for treatment of thalassemia major. Biol Blood Marrow Transplant. 2018;24(10):2119-26.

35. Pakbaz Z et al. Serum ferritin underestimates liver iron concentration in transfusion independent thalassemia patients as compared to regularly transfused thalassemia and sickle cell patients. Pediatr Blood Cancer. 2007:49(3):329-32.

36. Borgna-Pignatti $C$ et al. Survival and complications in patients with thalassemia major treated with transfusion and deferoxamine. Haematologica. 2004;89(10):1187-93.

37. Porter J et al, "Iron overload and chelation," Porter J, Viprakasit V, Kattamis A (eds.), Guidelines for the Management of Transfusion Dependent Thalassaemia (TDT)
(2014). $3^{\text {rd }}$ edition, Nicosia: Thalassaemia International Federation.

38. Kuragano T et al. Association between hemoglobin variability, serum ferritin levels, and adverse events/mortality in maintenance hemodialysis patients. Kidney Int. 2014;86(4):845-54.

39. Sullivan $\mathrm{S}$ et al. Budget impact analysis-principles of good practice: report of the ISPOR 2012 budget impact analysis good practice II task force. Value Health. 2014;17(1):5-14.

40. The National Institute for Health and Care Excellence (NICE). The guidelines manual. 7: assessing cost effectiveness. 2012. Available at: https://www.nice.org.uk/process/ pmg6/chapter/assessing-costeffectiveness. Last accessed: 7 April 2020.

41. Institute for Clinical and Economic Review (ICER). Sickle cell disease: evidence report. 2020. Available at: https://icer-review.org/material/ sickle-cell-disease-evidence-report/. Last accessed: 2 June 2020.

42. Sobhani $\mathrm{S}$ et al. Serum ferritin levels and irregular use of iron chelators predict liver iron load in patients with major beta thalassemia: a cross-sectional study. Croat Med J. 2019;60(5):405-13.

43. Porter $\mathrm{J}$ et al. Limitations of serum ferritin to predict liver iron concentration responses to deferasirox therapy in patients with transfusion-dependent thalassaemia. Eur J Haematol. 2017;98(3):280-8.

44. Wood J. Use of magnetic resonance imaging to monitor iron overload. Hematol Oncol Clin North Am. 2014:28(4):747-64

45. Wood J. Guidelines for quantifying iron overload. Hematology Am Soc Hematol Educ Program. 2014;2014(1):210-5 